\title{
Comparison of GPS TEC measurements with IRI TEC prediction at the equatorial latitude station, Chumphon, Thailand
}

\author{
P. Kenpankho ${ }^{1}$, K. Watthanasangmechai ${ }^{1}$, P. Supnithi ${ }^{1}$, T. Tsugawa ${ }^{2}$, and T. Maruyama ${ }^{2}$ \\ ${ }^{1}$ Faculty of Engineering, King Mongkut's Institute of Technology Ladkrabang, Ladkrabang, Bangkok 10520, Thailand \\ ${ }^{2}$ Space Environment Group, National Institute of Information and Communications Technology, \\ Nukuikita, Koganei, Tokyo 184-8795, Japan
}

(Received June 9, 2010; Revised December 8, 2010; Accepted January 25, 2011; Online published June 14, 2011)

\begin{abstract}
We have analyzed the total electron content (TEC) derived from dual-frequency GPS receivers (GPS TEC) at the Chumpon station, Thailand, during the period 2004-2006. The diurnal, monthly, and seasonal variation in the measured TEC is compared with the TEC derived from the IRI-2007 model as well as the TEC obtained from the International GNSS service (IGS). To date, TEC data at equatorial latitudes are limited. The Chumphon station $\left(10.72^{\circ} \mathrm{N}, 99.37^{\circ} \mathrm{E}\right)$ is located at the equatorial latitude and the dip latitude of $3^{\circ} \mathrm{N}$. The TEC from the IRI-2007 model is based on the actual $F_{2}$ plasma frequency $\left(f_{\mathrm{o}} F_{2}\right)$ measurement. The results of our study show that the TEC derived from the IRI-2007 model agrees with the GPS TEC data mostly in the morning hours, but that it generally underestimates the GPS TEC. The maximum differences are about 15 TECU during the daytime and 5 TECU during the nighttime. The underestimation is more evident at daytime than at nighttime. The noon-bite out phenomena are clearly seen for the IRI-2007 TEC, but not on the IGS TEC and GPS TEC. The general underestimation of the IRI-2007 model can be explained from the exclusion of the plasmasphere, whereas the large difference during noon bite-outs is caused by the difference in the slab thickness in the ionosphere between the IRI-2007 model and the actual measurement. When compared with the TEC from the IGS model, the TEC measurements at Chumpon appear to be quite similar.
\end{abstract}

Key words: GPS TEC, IRI-2007 TEC, IGS TEC, TEC comparison, TEC measurement, TEC prediction, equatorial latitude.

\section{Introduction}

The Global Position System (GPS), low-orbit navigation satellites, such as TRANSIT, and space technologies set the need to improve our understanding of the structure and activities of both the topside and bottomside ionospheres. Total Electron Content (TEC) is an important ionospheric parameter which directly affects the propagation of radio waves through the ionosphere. In the equatorial region, the TEC gradient may be one cause of the equatorial bubbles phenomenon (Yeh et al., 1979; Das Gupta et al., 1983; Rama Rao et al., 2004). TEC measurements assist in the development of ionospheric models, such as the International Reference Ionosphere (IRI) (Bilitza, 2001; Bilitza and Reinisch, 2008). The increase in the amount of TEC data that have become available during the last decades has largely been due to the rapid increase in the amount of Global Position System TEC (GPS TEC) data over land. The increasing number of GPS sites has provided an important database to study the ionosphere. Compared with the long record of over 70 years of ionospheric observation from ground-based measurements, TEC records from GPS are relatively short. Many published studies report comparisons of the measured TEC data obtained from different

Copyright (C) The Society of Geomagnetism and Earth, Planetary and Space Sciences (SGEPSS); The Seismological Society of Japan; The Volcanological Society of Japan; The Geodetic Society of Japan; The Japanese Society for Planetary Sciences; TERRAPUB.

doi:10.5047/eps.2011.01.010 techniques at various locations with various models, such as the IRI models (Bilitza et al., 1998; Jakowski et al., 1998; Ezquer et al., 1998, 2004; Huang and Reinisch, 2001; Sethi et al., 2001; Gulyaeva et al., 2002; Belehaki et al., 2003, 2004; Orús et al., 2003; Jodogne et al., 2004; Mosert et al., 2004). However, at the equatorial latitudes, such as at Chumphon station, Thailand, comparisons between TEC based on observation and that of the IRI models are scarce.

The objective of the study reported here was to compare the GPS TEC data recorded at the equatorial latitudinal location in Chumphon station, Thailand with the TEC obtained from the IRI-2007 model (Bilitza, 2001; Bilitza and Reinisch, 2008) and the IGS TEC. This monitoring station is a part of the South East Asia Low Latitude Ionosphere Observation Network (SEALION) (Maruyama et al., 2007). The aims of SEALION are to observe, monitor, and forecast the ionospheric variation in the Asia Pacific region near the magnetic equator. It is a joint project among the following institutions and countries: National Institute of Information and Communications Technology (NICT), Japan, King Mongkut's Institute of Technology Ladkrabang (KMITL), Thailand, Chiang Mai University (CMU), Thailand, National Institute of Aeronautics and Space (LAPAN), Indonesia, Hanoi Institute of Geophysics (HIG), Vietnamese Academy of Science and Technology, Vietnam, Center for Space Science and Applied Research (CSSAR), Chinese Academy of Sciences, China, and Ky- 
oto University, Japan. The GPS TEC data measured during the period 2004-2006 were analyzed and compared to the IRI models and IGS TEC based on the diurnal, monthly, and seasonal variations.

\section{Data Used \\ 2.1 GPS TEC data}

The GPS TEC data used in this study were recorded by the GPS receiver $\left(10.72^{\circ} \mathrm{N}, 99.37^{\circ} \mathrm{E}\right)$ from 2004 to 2006. TEC is defined as the total electron content (electron $/ \mathrm{m}^{2}$ ) of a vertical column of $1-\mathrm{m}^{2}$ cross-section (Goodwin et al., 1995). This definition of TEC is actually the definition of the vertical TEC (VTEC) through the piercing point with the obliquity factor (Lin, 2001; Brunini et al., 2004; Cabrera et al., 2005). The slant TEC (STEC) is defined as the line integral of the electron density from all GPS satellites visible from each of these receivers above a user-specified elevation cut-off angle (usually $15^{\circ}$ ) (Cabrera et al., 2005; Jin and Park, 2007; Zeilhofer et al., 2009). In the GPS system, every satellite transmits the signals on two frequencies $\left(f_{1}=1575.42 \mathrm{MHz}\right.$ and $\left.f_{2}=1227.60 \mathrm{MHz}\right)$. The dual-frequency GPS receiver is used for the GPS TEC measurement system, which consists of a micro strip antenna, an amplifier, a TEC Meter, and a computer. The GPS receiver starts functioning when it continuously receives between four and 12 GPS signals that will lead to the computation of the STEC values.

The STEC from a satellite to a receiver can be obtained from the difference between the pseudoranges $\left(P_{1}\right.$ and $\left.P_{2}\right)$ or the difference between the carrier phases $\left(L_{1}\right.$ and $\left.L_{2}\right)$ of the two frequencies (Blewitt, 1990), i.e.,

$$
\text { STEC }=\frac{2\left(f_{1} f_{2}\right)^{2}}{k\left(f_{1}^{2}-f_{2}^{2}\right)}\left(P_{2}-P_{1}\right)+\tau^{\mathrm{r}}+\tau^{\mathrm{s}},
$$

or

$$
\mathrm{STEC}=\frac{2\left(f_{1} f_{2}\right)^{2}}{k\left(f_{1}^{2}-f_{2}^{2}\right)}\left(L_{1} \lambda_{1}-L_{2} \lambda_{2}\right)+\varepsilon^{\mathrm{r}}+\varepsilon^{\mathrm{s}},
$$

where $k$, related to the ionosphere refraction, is 80.62 $\left(\mathrm{m}^{3} / \mathrm{s}^{2}\right) ; \lambda_{1}$, and $\lambda_{2}$ are the wavelengths corresponding to $f_{1}$ and $f_{2}$, repectively; $\tau^{\mathrm{r}}$, and $\varepsilon^{\mathrm{r}}$ are the differential code biases corresponding to the pseudoranges $\left(P_{1}\right.$ and $\left.P_{2}\right)$, and the carrier phases $\left(L_{1}\right.$ and $\left.L_{2}\right)$, respectively; $\tau^{\mathrm{s}}$, and $\varepsilon^{\mathrm{s}}$ are the inter-frequency biases corresponding to the pseudoranges $\left(P_{1}\right.$ and $\left.P_{2}\right)$, and the carrier phases $\left(L_{1}\right.$ and $\left.L_{2}\right)$, respectively.

VTEC, in $\mathrm{el} / \mathrm{m}^{2}$, can be computed from $\mathrm{Ma}$ and Maruyama (2003) as

$$
\mathrm{VTEC}=\mathrm{STEC} \times \cos \chi,
$$

where the zenith angle $\chi$ is expressed as

$$
\chi=\arcsin \left(\frac{R_{\mathrm{E}} \cos \alpha}{R_{\mathrm{E}}+h}\right),
$$

where $\alpha$ is the elevation angle of the satellite, $R_{\mathrm{E}}$ is the mean radius of the Earth, and $h$ is the height of the ionospheric layer, which is assumed to be $400 \mathrm{~km}$.

The STEC that is computed based on the carrier phase in Eq. (2) is generally less noisy than that from Eq. (1); however, the ambiguity in the integer value of $L$, known as a cycle slip, often arises. The cycle slip correction can typically be made with the aid of pseudorange difference information. To obtain the VTEC, we compute

$$
\mathrm{VTEC}=\left(\mathrm{STEC}-b_{\mathrm{s}}-b_{\mathrm{r}}\right) \times \cos \chi,
$$

where $b_{\mathrm{s}}$ and $b_{\mathrm{r}}$ are the estimated satellite and receiver biases, respectively. In this work, the satellite bias is obtained from NICT based on the GPS Earth Observation Network (GEONET), set up by the Geographical Survey Institute (GSI) of Japan, which has more than 1,000 GPS receivers spread throughout Japan (Miyazaki et al., 1997). The receiver bias for a single receiver at Chumpon station is calculated using the minimum variance method (Ma and Maruyama, 2003).

\subsection{IRI TEC data}

With the goal of establishing an international standard for the specification of ionospheric parameters based on all worldwide available data from both ground-based and satellite observations, the International Reference Ionosphere (IRI) project was initiated by the Committee on Space Research (COSPAR) and by the International Union of Radio Science (URSI) in the late 1960s. COSPAR and URSI specifically asked for an empirical IRI model to avoid the uncertainties of the evolving theoretical understanding of ionospheric processes and coupling to the regimes below and above. The IRI model is continually upgraded as new data and new modeling approaches become available, and this process has resulted in several major milestone editions of IRI (Rawer et al., 1978a, b, 1981; Bilitza, 1990, 2001; Bilitza and Rawer, 1996) that progress from a set of tables for typical conditions to a global model for all phases of the solar cycle. More information on the IRI project, including information on the IRI Newsletter and the IRI electronic mailer, can be found on the IRI homepage at http://IRI.gsfc.nasa.gov/.

The corresponding IRI TEC predictions (IRI TEC) are calculated from the IRI-2007 models (Bilitza and Reinisch, 2008) using the location, dates, and period of time as inputs to the model. The IRI-2007, a new empirical standard model of the ionosphere, is improved from the limitations of the previous IRI-2001 model. To predict the IRI TEC from IRI-2007, we can access the site at http://ccmc. gsfc.nasa.gov/modelweb/models/iri_vitmo.php/, which has more recently also become available as an interactive web interface accessible from the IRI homepage. In this study, we use the IRI-2007 TEC with the $F_{2}$ plasma frequency $\left(f_{\mathrm{o}} F_{2}\right)$ measurement option.

\subsection{IGS TEC data}

IGS TEC data are maintained and monitored by the International GNSS service (IGS). The IGS relies on an international network of over 350 continuously operating dualfrequency GPS stations (Dow et al., 2009). The Central Bureau for the service is located at the Jet Propulsion Laboratory, which maintains the Central Bureau Information System (CBIS) and ensures access to IGS products and information. An international Governing Board oversees all aspects of the IGS. The IGS has been an approved service of the International Association of Geodesy since 1994 and recognized as a member of the Federation of Astronomi- 


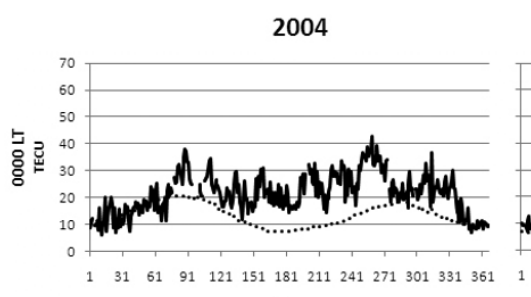

Days

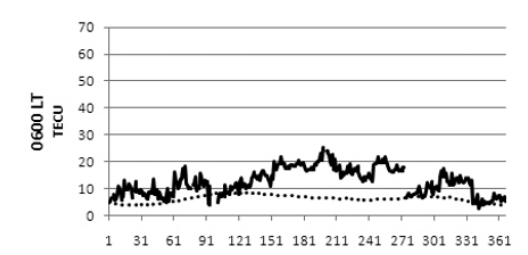

Days

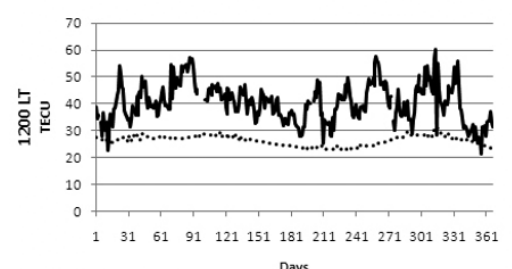

Days

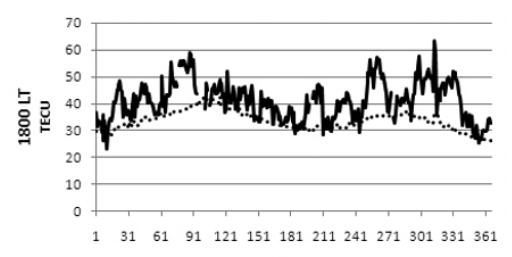

Days

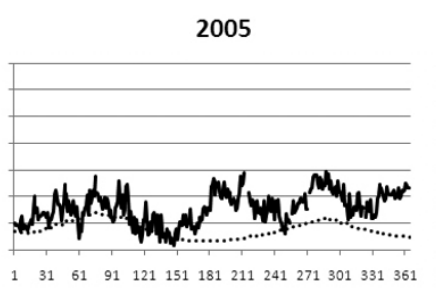

Days

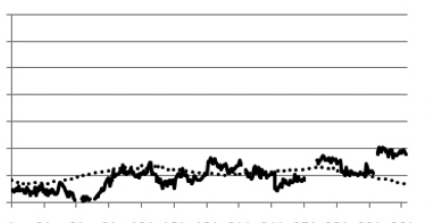

Days

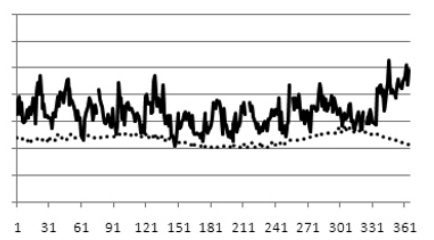

Days

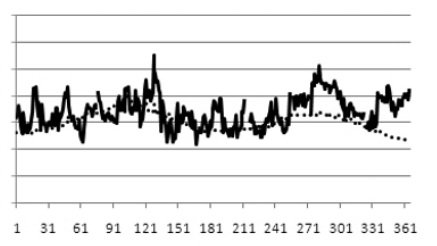

Days

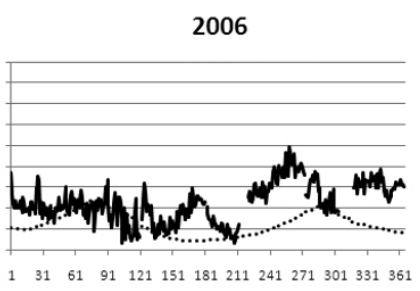

Days

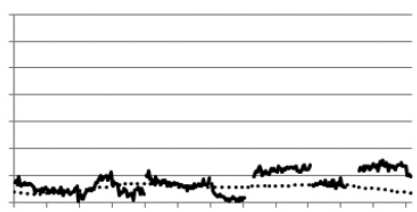

$\begin{array}{lllllllllllllllll}1 & 31 & 61 & 91 & 121 & 151 & 181 & 211 & 241 & 271 & 301 & 331 & 361\end{array}$

Days

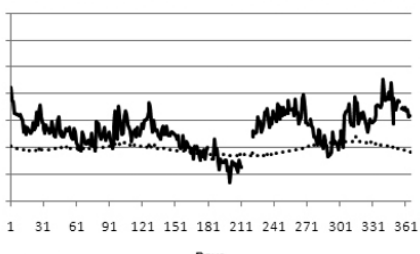

Days

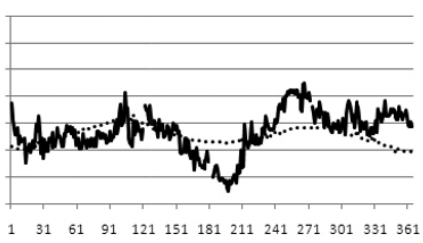

Days

Fig. 1. Diurnal median values of GPS TEC and IRI-2007 TEC at the Chumphon station for 0000 LT, 0600 LT, 1200 LT and 1800 LT during the period 2004-2006.

cal and Geophysical Data Analysis Services (FAGS) since 1996. The IGS collects, archives, and distributes GPS observation data sets. It provides the TEC map data available on the Internet, and these data can be accessed from the File Transfer Protocol (FTP) site: ftp://igscb.jpl.nasa.gov/.

In this work, we use the 2-h text data of global TEC maps with the different code biases in the IONEX (The IONosphere Map EXchange) format via the following FTP site: ftp://cddis.gsfc.nasa.gov/pub/gps/products/ionex/. The final TEC map data estimates are provided by three centers on the same day (COD, JPL, and UPC with associated final product labels CODG, JPLG, and UPCG) together with the corresponding final combined IGS values (labeled as IGSG).

\section{Results of the Analysis}

\subsection{Diurnal variation of the GPS TEC and TEC from} the IRI-2007 model

Figure 1 shows the comparison between the diurnal median values of GPS TEC and IRI-2007 TEC (in TEC units of $10^{16} / \mathrm{m}^{2}=1 \mathrm{TECU}$ ) at Chumphon station from 2004 to 2006, a period of low solar activity. Each curve shows the variation of TEC versus the hours representing different times of day, including 0000 LT (midnight), 0600 LT (pre-sunrise), 1200 LT (midday), and 1800 LT (pre-sunset), respectively. The solid line denotes GPS TEC from our observation and the dotted line is the IRI-2007 predictions.
The IRI-2007 model underestimates the observed TEC from GPS TEC data because the GPS TEC computes the TEC from ground all the way up to the plasmasphere, but the IRI-2007 model includes the ionosphere only. The largest deviation is evident at 1200 LT in 2004. For 2004 and 2005, the large difference is seen at midday. The largest differences between GPS TEC values and IRI-2007 TEC values are at the midday time in 2004. The GPS TEC values differ from IRI-2007 TEC values at about 15 TECU. The IRI-2007 model predicted the TEC data well at pre-sunset hours in 2004 and 2005.

\subsection{Seasonal comparison of GPS TEC, IGS TEC and IRI TEC}

Since the IRI 2007 model is based on the TEC derived from the ionogram, while the GPS TEC and IGS TEC data are derived from GPS data, it would be interesting to compare them with the IGS TEC obtained from the GIM TEC map. We use the IGS TEC map data at $10^{\circ} \mathrm{N}$ and $100^{\circ} \mathrm{E}$, the location of Singapore, which is the nearest monitoring location to the Chumphon station. In Fig. 2, we show the seasonal median TEC comparison of GPS TEC, IGS TEC, and IRI-2007 TEC from 2004 to 2006. The periods of study are classified into three seasons, including the equinox (March, April, September, and October), summer (May, June, July, and August), and winter (January, February, November, and December).

As seen from Fig. 2, the IRI model generally underes- 


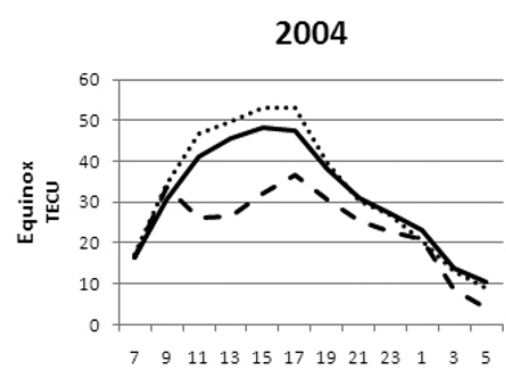

Local time

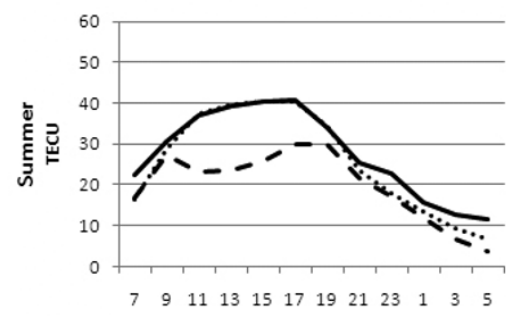

Local time

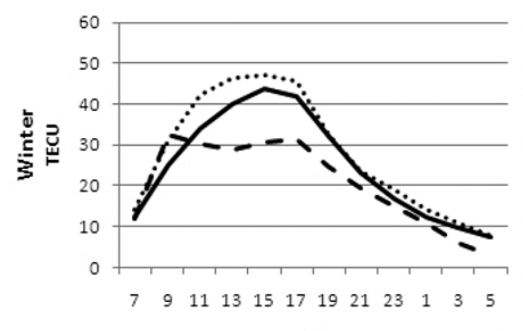

Local time
2005

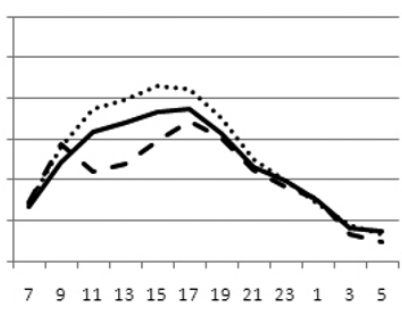

Local time

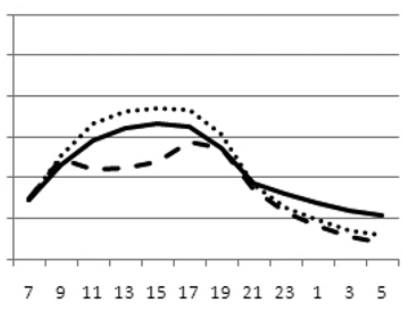

Local time

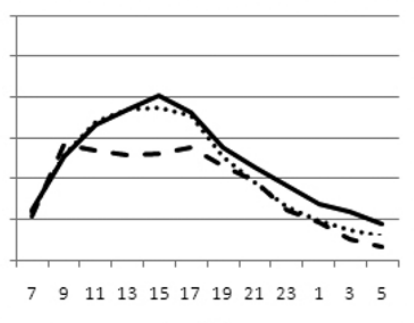

Local time
2006

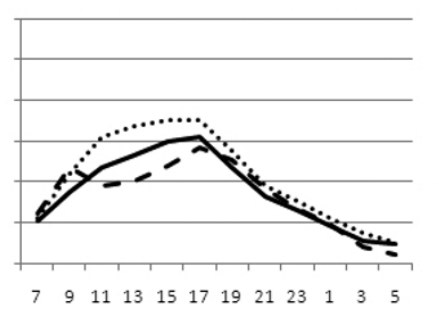

Local time

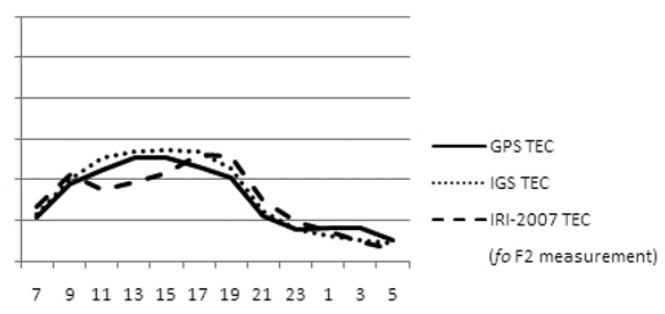

Local time

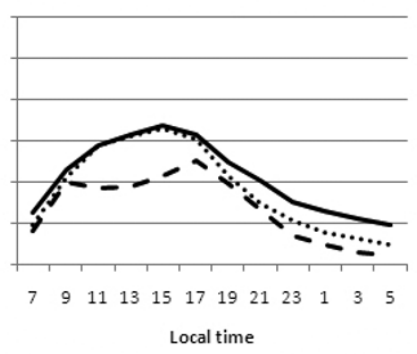

Fig. 2. Seasonal median values of GPS TEC, IGS TEC and IRI-2007 TEC at a Chumphon station for the three seasons, namely, equinox, summer and winter, respectively, during the period 2004-2006.

timates the observed TEC, with the underestimation being more evident at daytime than nighttime, particularly during the noon bite-out periods. The noon-bite out events are clearly seen on the IRI-2007 TEC, but not on the IGS TEC and GPS TEC. The IRI-2007 TEC and the observed TEC are very similar during the nighttime of the equinox in 2005 and 2006. A similar seasonal trend on GPS TEC and IRI TEC (IRI-2001 TEC) has been reported by Mosert et al. (2007) using data from Ebro $\left(40.8^{\circ} \mathrm{N}, 0.5^{\circ} \mathrm{E}\right)$. The significant difference observed is that GPS TEC is greater than IRI TEC according to the altitude (altitudes are about 20,200 $\mathrm{km}$ and 2,000 $\mathrm{km}$ for the GPS TEC and IRI TEC, respectively). In addition, Jin and Park (2007) studied the comparison of TEC at the grid point $\left(37.5^{\circ} \mathrm{N}, 127.0^{\circ} \mathrm{E}\right)$ over South Korea, estimated from GPS and IRI-2001 TEC in different seasons. Their results showed that maximum TEC values occurred at about the noontime, between $1100 \mathrm{LT}$ and $1500 \mathrm{LT}$.

The IGS TEC is generally higher than the GPS TEC at about 5 TECU during the daytime of the equinox, but it is lower than the GPS TEC at about 5 TECU during the nighttime in the winter of 2005 and 2006. The satellite biases derived by NICT do not provide the accuracy bias estimation (Ma and Maruyama, 2003). However, Ma and Maruyama (2003) calculated that the standard deviation of the satellite bias in GEONET ranges from 0.23 to 1.89 TECU for the 9-day windows. To determine the receiver bias, we esti- mate the receiver biases on the 5-day average of STEC and TEC values for each month during 2004-2006. We find that the average receiver bias is up to 4.28 TECU. For the IGS TEC, the data from TEC map has a root-mean square error (RMSE) of about 4.53 TECU (Hernandez-Pajares et al., 2008). The IRI-2007 values follow the IGS model more closely in the early morning than any other time of day. The maximum difference between the GPS TEC and the IRI-2007 TEC are about 15 TECU during the daytime and about 5 TECU at the nighttime.

The large difference between the GPS TEC and IRI TEC during noontime indicates that the ionosphere at Chumpon or the equatorial area is expanded to cover a larger thickness than at other times. At the equatorial latitude, the steepest gradients, sharp peaks and deep valleys, and density crests are on both sides of the equator, as explained by Bilitza and Reinisch (2008). The occurrence of a prominent trough accompanied by maximum TEC values in the pre-noon and the afternoon at equatorial latitudes is referred to as a noon bite-out, which is a characteristic feature at an equatorial station that falls in the trough of the equatorial anomaly (Maeda, 1955; Rastogi, 1959). The noon bite-out phenomenon is the result of interaction and the relative role played by the production, loss, and movements terms in the continuity equation of the electron density at the peak of the layer. The TEC movement includes the effects of vertical drift, horizontal diffusion of ionization along the field 
lines, and neutral winds. Martyn (1955) and Rao (1966) showed that the pre-noon peak in the diurnal variation at equatorial latitudes is influenced by horizontal winds in addition to production and loss processes, while the afternoon peak is determined by vertical drifts and diffusion.

The IRI-TEC model is not directly constructed from the measured TEC database, but the TEC calculation is conducted from $f_{\mathrm{o}} F_{2}$. The height profile of electron density is calculated based on the $f_{\mathrm{o}} F_{2}$, step-by-step. The $f_{\mathrm{o}} F_{2}$ is the most important parameter in the IRI model because IRI historically is based on an extension of the CCIR $f_{\mathrm{o}} F_{2}$ model. The density profile is then integrated along the vertical line to obtain TEC. In this process, topside electron density may not be adequately modeled, i.e., the thickness is too small for IRI topside density profile. The discrepancy between TEC measurements and IRI results suggest that this error is most significant during the hours when the noon bite-out develops. It is larger than the plasmaspheric model that was previously reported (Bishop et al., 2009). The relative contribution of plasmasphere TEC (P-TEC) is larger in the nighttime (Yizengaw et al., 2008). In other words, the slab thickness becomes quite large during the noon bit-out of $f_{\mathrm{o}} F_{2}$. Thus, during the noon bite-out periods, this discrepancy cannot be ascribed to ignorance of the plasmasphere in the IRI model. Rather. it should be the difference of slab thickness in the ionosphere.

\section{Summary}

In this work, the GPS TEC derived from the TEC data at Chumpon equatorial station, Thailand is compared with the IRI TEC (IRI-2007 TEC) and the IGS TEC from 2004 to 2006. The maximum differences are about 15 TECU during the daytime and about 5 TECU during the nighttime. When compared with the IGS TEC, we find that the GPS TEC measurements from the Chumphon station and those from the IGS model are quite similar, and both are higher than the TEC predicted from the IRI-2007 model. The IRI2007 model fits the GPS TEC data mostly in the morning hours, but generally underestimates the GPS TEC since the plasmasphere is not included in the model. The underestimation is more apparent at daytime than nighttime, particularly during the noon bite-outs. This discrepancy is larger than the effects of the plasmaspheric model that was previously reported. This difference during daytime indicates that it is due to the difference of slab thickness in the ionosphere between the IRI model and the measured data.

Acknowledgments. The authors are grateful to the National Institute of Information and Communications Technology (NICT), Japan, for the financial support and necessary equipment. In addition, the authors would like to credit the IGS Ionospheric Working Group for the IGS TEC data used in this paper. We would also like to thank the reviewers for the comments which were very helpful in revising the manuscript.

\section{References}

Belehaki, A., N. Jakowski, and B. W. Reinisch, Comparison of ionospheric ionization measurements over Athens using ground ionosonde and GPS derived TEC values, Radio Sci., 38(6), 1105, 2003.

Belehaki, A., N. Jakowski, and B. W. Reinisch, Plasmaspheric electron content derived from GPS TEC and digisonde ionograms, Adv. Space Res., 33, 237-833, 2004.
Bilitza, D., International Reference Ionosphere: IRI-90, National Space Science Data Center, Rep. 90-22, Greenbelt, Maryland, 1990.

Bilitza, D., International Reference Ionosphere 2000, Radio Sci., 38(6), 261-275, 2001.

Bilitza, D. and K. Rawer, International Reference Ionosphere, in The Upper Atmosphere-Data Analysis and Interpretation, pp. 735-772, Springer-Verlag, Berlin, Heidelberg, 1996.

Bilitza, D. and B. W. Reinisch, International Reference Ionosphere 2007: Improvements and new parameters, Adv. Space Res., 42, 599-609, 2008.

Bilitza, D., M. Hernandez-Pajares, J. M. Juan, and J. Sanz, Comparison between IRI and GPS-IGS derived electron content during 1991-97: first results, Phys. Chem. Earth, 24(4), 311-319, 1998.

Bishop, G. J., J. A. Secan, and S. H. Delay, GPS TEC and the plasmasphere: Some observations and uncertainties, Radio Sci., 44, RSOA26, doi:10.1029/2008rs004037, 2009.

Blewitt, G., An automatic editing algorithm for GPS data, Geophys. Res. Lett., 17, 199-202, 1990.

Brunini, C., A. Meza, F. Azpilicuata, M. A. Van Zele, M. Gende, and A. Diaz, A new ionosphere monitoring technology based on GPS, Astrophys. Space Sci., 290, 415-429, 2004.

Cabrera, M. A., R. G. Ezquer, and S. M. Radicella, Predicted and measured slant ionospheric electron content, J. Atmos. Terr. Phys., 67, 1566-1577, 2005.

Das Gupta, A., S. Basu, J. Aarons, J. A. Klobuchar, Su. Basu, and A. Bushby, VHF amplitude scintillations and associated electron content depletions as observed at Arequipa, Peru, J. Atmos. Terr. Phys., 45, 1526, 1983.

Dow, J. M., R. E. Neilan, and C. Rizos, The International GNSS Service in a changing landscape of Global Navigation Satellite Systems, J. Geod., 83, 191-198, doi:10.1007/s00190-008-0300-3, 2009.

Ezquer, R., C. Jadur, and M. Mosert, IRI95 TEC predictions for the South American peak of the equatorial anomaly, Adv. Space Res., 22(6), 811814, 1998.

Ezquer, R., C. Brunini, M. Mosert, A. Meza, R. del V. Oviedo, E. Kiorcheff, and S. M. Radicella, GPS-VTEC measurements and IRI predictions in the South American sector, Adv. Space Res., 34, 2035-2043, 2004.

Hernandez-Pajares, M., J. M. Juan, J. Sanz, R. Orus, A. Garcia-Rigo, J. Feltens, A. Komjathy, S. C. Schaer, and A. Krankowski, The IGS VTEC maps: a reliable source of ionospheric information since 1998, J. Geod., 83, 263-275, 2008.

Huang, X. and B. W. Reinisch, Vertical electron content from ionograms in real time, Radio Sci., 36(2), 335-342, 2001.

Goodwin, G. L., J. H. Silby, K. J. Lynn, A. M. Breed, and E. A. Essex, GPS satellite measurements: ionospheric slab thickness and total electron content, J. Atmos. Sol.-Terr. Phys., 57(14), 1723-1732, 1995.

Gulyaeva, T., X. Huang, and B. W. Reinisch, Plasmaspheric extension of topside electron density profiles, Adv. Space Res., 29(6), 825-831, 2002. Jakowski, N., E. Sardon, and S. Schluter, GPS-Based TEC observations in comparison with IRI95 and the European TEC model NTCM2, $A d v$. Space Res., 22(6), 803-806, 1998.

Jin, S. G. and P. H. Park, GPS ionospheric tomography: A comparison with the IRI-2001 model over South Korea, Earth Planets Space, 59, 287-292, 2007.

Jodogne, J. C., H. Nebdi, and R. Warnant, GPS TEC and ITEC from digisonde data compared with NEQUICK model, Adv. Sapce Res., 2, 269-273, 2004.

Lin, L., Remote sensing of ionosphere using GPS measurements, in Proceedings Asian Association on Remote Sensing, pp. 69-74, Singapore, 2001.

Ma, G. and T. Maruyama, Derivation of TEC and estimation of instrumental biases from GEONET in Japan, Ann. Geophys., 21, 2083-2093, 2003.

Maeda, H., Horizontal wind systems in the ionospheric E region deduced from the dynamo theory of geomagnetic Sq variation, Part I, J. Geomag. Geoelectr., 7, 121-132, 1955.

Martyn, D. F., The Physics of the Ionosphere, The Physical Society, London, 260, 1955.

Maruyama, T., M. Kawamura, S. Saito, K. Nozaki, H. Kato, N. Hemmakorn, T. Boonchuk, T. Komolmis, and C. Ha Duyen, Low latitude ionosphere-thermosphere dynamics studies with inosonde chain in Southeast Asia, Ann. Geophys., 25, 1569-1577, 2007.

Miyazaki, S., T. Saito, M. Sasaki, Y. Hatanaka, and Y. Iimura, Expansion of GSI's nationwide GPS array, Bull. Geogr. Surv. Inst., 43, 23-34, 1997.

Mosert, M., R. Ezquer, C. Jadur, and R. del V. Oviedo, Time variation of total electron content over Tucuma, Argentina, Geof. Int., 43(2), 143$151,2004$. 
Mosert, M., M. Gende, C. Brunini, R. Ezquer, and D. Altadill, Comparison of IRI TEC predictions with GPS and digisonde measurements at Ebro, Adv. Space Res., 39, 841-847, 2007.

Orús, R., M. Hernandez-Pajares, J. M. Juan, J. Sanz, and M. Garcia Fernandez, Validation of the GPS TEC maps with topex data, Adv. Space Res., 31(3), 621-627, 2003.

Rama Rao, P. V. S., K. Niranjan, D. S. V. V. D. Prasad, S. Gopi Krishna, and S. Tulasi Ram, Simultaneous Observations of VHF and L-band Scintillations from an Indian Low Latitude Station, Waltair $\left(17.7^{\circ} \mathrm{N}\right.$, 83. $3^{\circ}$ E), Proc. of IBSS-2004, Trieste, Italy, 2004.

Rao, B. C. N., Control of equatorial Spread-F by the F layer height, $J$. Atmos. Terr. Phys., 28, 1207-1217, 1966.

Rastogi, R. G., The diurnal development of the anomalous equatorial belt in the F2 region of the ionosphere, J. Geophys. Res., 64, 727-732, 1959.

Rawer, K., D. Bilitza, and S. Ramakrishnan, International Reference Ionosphere, International Union of Radio Science (URSI), Brussels, Belgium, 1978a.

Rawer, K., D. Bilitza, S. Ramakrishnan, and M. Sheikh, Intentions and buildup of the International Reference Ionosphere, in Operational Modeling of the Aerospace Propagation Environment, AGARD Conf. Proc., 238, 6.1-6.10, 1978b.
Rawer, K., J. V. Lincoln, and R. O. Conkright, International Reference Ionosphere-IRI 79, World Data Center A for Solar-Terrestrial Physics, Report UAG-82, Boulder, Colorado, 1981.

Sethi, N. K., V. K. Pandey, and K. K. Mahajan, Comparative study of TEC with IRI model for solar minimum period at low latitude, Adv. Space Res., 27(1), 45-48, 2001.

Yeh, K. C., H. Soicher, C. H. Liu, and E. Borelli, Ionospheric bubbles observed by the Faraday rotation method at Natal, Brazil, Geophys. Res. Lett., 6, 473-475, 1979.

Yizengaw, E., M. B. Moldwin, D. Galvan, B. A. Iijima, A. Komjathy, and A. J. Mannucci, Global plasmapheric TEC and its relative contribution to GPS TEC, J. Atmos. Terr. Phys., 70, 1541-1548, 2008.

Zeilhofer, C., M. Schmidt, D. Bilitza, and C. K. Shum, Regioal 4-D modeling of the ionospheric electron density from satellite data and IRI, $A d v$. Space Res., 43, 1669-1675, 2009.

P. Kenpankho (e-mail: $\quad$ kkpraser@kmitl.ac.th), K. Watthanasangmechai, P. Supnithi, T. Tsugawa, and T. Maruyama 